\title{
Tracking interactions: new ways of finding value in the use of museum websites
}

\author{
Seb Chan \\ Powerhouse Museum \\ 500 Harris St, Ultimo \\ Sydney NSW 1238, Australia.
}

\begin{abstract}
Museums have a poor record of extracting significant value from the analysis of traffic to their online content. Despite the advances in behaviour tracking on the web and the increasingly sophisticated use of visitor monitoring inside museum galleries, there has been far too little attention paid to the same online. At the same time, visitors to museums and cultural institutions are voluntarily sharing far more of their own data explicitly through social networking websites. This presentation will demonstrate a number of different online tracking techniques being used at the Powerhouse Museum in Sydney both to improve online content and delivery, as well as to apply learnings to the gallery and collection strategies.
\end{abstract}

